DOI: 10.12731/wsd-2018-1-30-37

УДК 574.474

\title{
АНАЛИЗ ДИНАМИКИ КЛИМАТИЧЕСКИХ ДАННЫХ НА ТЕРРИТОРИИ НП «БУЗУЛУКСКИЙ БОР»
}

\author{
Кожакин П.А., Хазиахметов Р.М.
}

Сегодня большое внимание уделяется изменению климатических условий в целом на планете и отдельных ее регионах, изучению динамики основных их компонентов в различных экосистемах и их влияние. Особо важно проследить данные изменения в аридных экосистемах и на гранииах распространения видов, изменение эдификаторов и ареалов (вредителей, болезней). Необходимо выявить экологические риски для особо охраняемых природных территорий, которым и является национальный парк.

В статье приведена природно-климатическая характеристика федерального государственного учреждения «Национальный парк «Бузулукский бор»», который является уникальной экосистемой в степной зоне Южного Урала и южной границей распространения Сосны обыкновенной (Pinus sylvestris). Проведен анализ данных метеостанции «Боровая ЛОС» за последние сто лет среднегодовых показателей температуры, осадков и относительной влажности воздуха. В результате исследования отчетливо прослеживается тренд повышения температуры, осадков на территории бора. Колебания влажности за последние сто лет незначительные и наблюдается небольшая обратная корреляция между температурой и численностью осадков.

Ключевые слова: Бузулукский бор; природно-климатическая характеристика; положительный тренд температуры.

\section{ANALYSIS OF CLIMATIC DATA DYNAMICS IN BUZULUKSKY BOR NATIONAL PARK}

\section{Kozhakin P.A., Haziahmetov R.M.}

Nowadays scientists pay much attention to climatic changes on the planet in general and its separate regions, to the study their basic components $d y$ namics in different ecosystems and their impact. It is particularly important to 
trace these changes in arid ecosystems and on the borders of species distribution area, as well as characteristic species changing.

The article presents the climatic characteristics of the Federal state institution "Buzuluksky Bor» National Park which is a unique ecosystem in the steppe zone of the southern Urals and Pine (Pinus sylvestris) southern boundary. The paper analyzes «Borovaya Forest Experimental Station» data of average annual temperature, precipitation and atmosphere relative humidity in the past hundred years. The study clearly shows a trend of temperature and precipitation increasing on the territory of the forest. Humidity fluctuations are insignificant in the last hundred years and a small invert correlation is observed between the temperature and strength of precipitation.

Keywords: Buzuluksky Bor; environment; positive temperature trend.

Бузулукский бор - хвойный лесной массив в степной зоне, расположен на границе Оренбургской и Самарской областей. В работе Е.Д. Годнева указывается об уникальности данного лесного массива, так как это один из южных пунктов распространения Сосны обыкновенной (Pinus sylvestris) в Европе и наиболее крупный ее остров на юго-востоке европейской части бывшего СССР. Так же он указывает его размеры в 111,6 тысяч га [1], которые не остаются постоянными, так Я. Н. Даркшевич пишет: «... с 1793 по 1843 год пожары уничтожили около 30 тыс. га леса». Указывается, что 1844 год принято считать началом ведения правильного лесного хозяйства [2].

Цель данной работы выявить тренд климатических показателей на территории ФГБУ «Национальный парк «Бузулукский бор».

Впервые охраняемая территория в бору была выделана в 1930 году, в 1936 году - водоохранная зона, к 1940 заповедная зона имела площадь в 10,5 тысяч га. Приказом Министерства Природных Ресурсов РФ № 1952-Р от 29 декабря 2007 года на территории лесного массива образован национальный парк.

Основные задачи его функционирования определены следующим образом:

1) сохранение природных комплексов, уникальных и эталонных природных участков и объектов, растительного и животного мира;

2) сохранение историко-культурных объектов;

3) экологическое и историко-культурное просвещение населения;

4) создание условий для регулируемого туризма и отдыха;

5) разработка и внедрение научных методов охраны природы и экологического просвещения; 
6) осуществление экологического мониторинга;

7) восстановление нарушенных природных и историко-культурных комплексов и объектов [3].

В физико-географическом отношении Бузулукский бор расположен в юго-восточной части Русской равнины - запад Общесыртовско-Предуральской возвышенно степной провинции.

В состав лесных угодий входят:

- основной массив общей площадью около 86,6 тысяч. га;

- широкая полоса пойменных лесов на р.Самара, протянувшаяся с запада на восток на 80 км;

- более 90 отдельных лесных колков, разбросанных на междуречьях рек Самара, Кутулук, Большой Кинель.

В геолого-геоморфологическом отношении лесной массив занимает гипсометрический уровень от 70 до 160 м над уровнем моря. Наибольшие отметки приходятся на сыртовые дубравы (до 220 или 230 метров) в междуречьях Боровка-Кутулук и Кутулук-Большой Кинель, а минимальная - 44 метров над уровнем моря у реки Самара выше села Богатое. На территории бора широко распространены молассовые отложения (красноцветные песчаники, конгломераты и аргиллиты татарского яруса пермской системы).

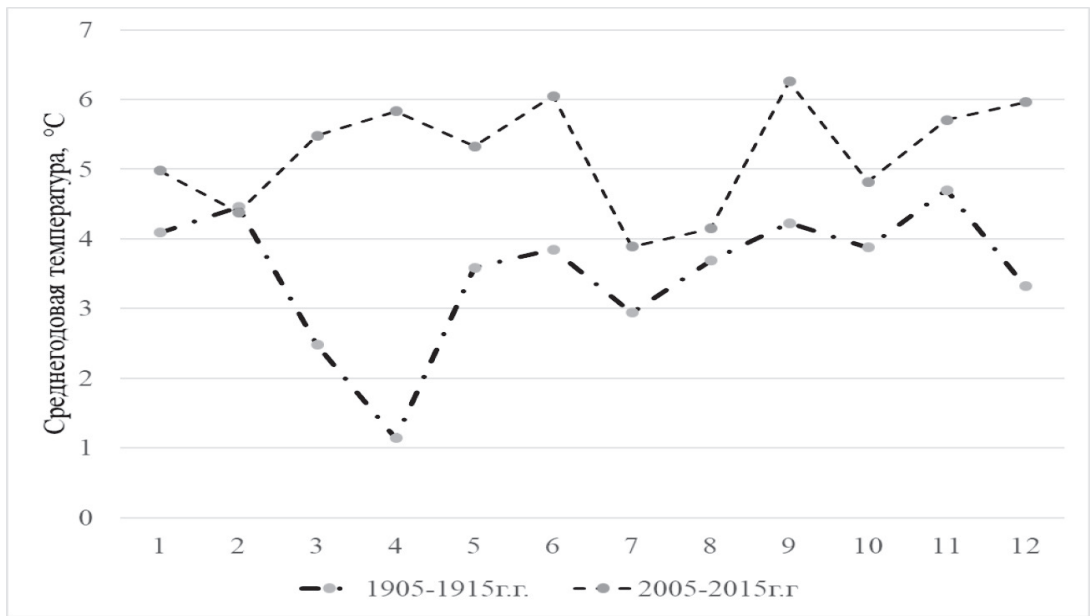

Рис. 1. График сравнительной динамики среднегодовой температуры с 1905 по 1915 гг. и с 2005 по 2015 гг. по материалам метеостанции «Боровая ЛОС» Распределение температур по годам представлено в таблице 1 
Подземные воды в национальном парке связаны с аллювиальным горизонтом, уровень в течение года изменяется от 2,1 до 4,5 метров и имеют низкую минерализацию [4].

Для климата Бузулукского бора характера хорошо выраженная континентальность. Наличие многолетних данных (с 1905 г. - образование метеостанции «Боровая ЛОС») по температуре, осадкам, относительной влажности воздуха позволяет проанализировать тенденции изменений температуры в сторону ее повышения, что хорошо видно из графика рисунка 1.

Таблица 1.

Распределение температур с 1905 по 1915 гг. и с 2005 по 2015 гг.

\begin{tabular}{|l|c|c|c|c|c|c|c|c|c|c|}
\hline $\mathbf{1 9 0 5}$ & $\mathbf{1 9 0 6}$ & $\mathbf{1 9 0 7}$ & $\mathbf{1 9 0 8}$ & $\mathbf{1 9 0 9}$ & $\mathbf{1 9 1 0}$ & $\mathbf{1 9 1 1}$ & $\mathbf{1 9 1 2}$ & $\mathbf{1 9 1 3}$ & $\mathbf{1 9 1 4}$ & $\mathbf{1 9 1 5}$ \\
\hline 4,09 & 4,46 & 2,48 & 1,14 & 3,59 & 3,85 & 2,94 & 3,69 & 4,23 & 3,88 & 4,7 \\
\hline $\mathbf{2 0 0 5}$ & $\mathbf{2 0 0 6}$ & $\mathbf{2 0 0 7}$ & $\mathbf{2 0 0 8}$ & $\mathbf{2 0 0 9}$ & $\mathbf{2 0 1 0}$ & $\mathbf{2 0 1 1}$ & $\mathbf{2 0 1 2}$ & $\mathbf{2 0 1 3}$ & $\mathbf{2 0 1 4}$ & $\mathbf{2 0 1 5}$ \\
\hline 4,98 & 4,38 & 5,48 & 5,83 & 5,33 & 6,05 & 3,89 & 4,15 & 6,26 & 4,82 & 5,71 \\
\hline
\end{tabular}

Минимальная среднегодовая температура на начало XX века составляла $1,14^{\circ} \mathrm{C}$ а максимальная 4,70 , в XXI 2,43 и $6,52^{\circ} \mathrm{C}$ соответственно. Таким образом, за 100 лет повышение среднегодовой температура составило $1,29-1,82^{\circ} \mathrm{C}$. Стандартная ошибка не превышает $0,24^{\circ} \mathrm{C}$.

В динамике осадков, представленных на рисунках 2 и 3 на начало XX и XXI веков так же прослеживается тренд в сторону повышения. Минимальные и максимальные среднегодовые показатели с 1905 по 1918 гг. составляют 28 и 64 мм. соответственно, а с 1985 по 2016 гг. 28,58 и 65,08 мм. Стандартная ошибка не превышает 2,5 мм. По сумме осадков минимальные и максимальные показатели составляют 352 и 768 мм соответственно для периода с 1905 по 1918 гг. и 343 и 781 мм соответственно с 1985 по 2016 гг.

Корреляционный анализ между показателями температуры и осадков ожидаемо показал почти полное отсутствие связи и составил минус 0,17 .

Среднегодовая относительная влажность воздуха на территории национального парка «Бузулукский бор» представлена с 1936 по 1983 г.г., что достаточно для выявления положительного или отрицательного тренда данного показателя, колеблется в диапазоне от 68,42 до 78,33\%. Данные по годам представлены на рисунке 4. 


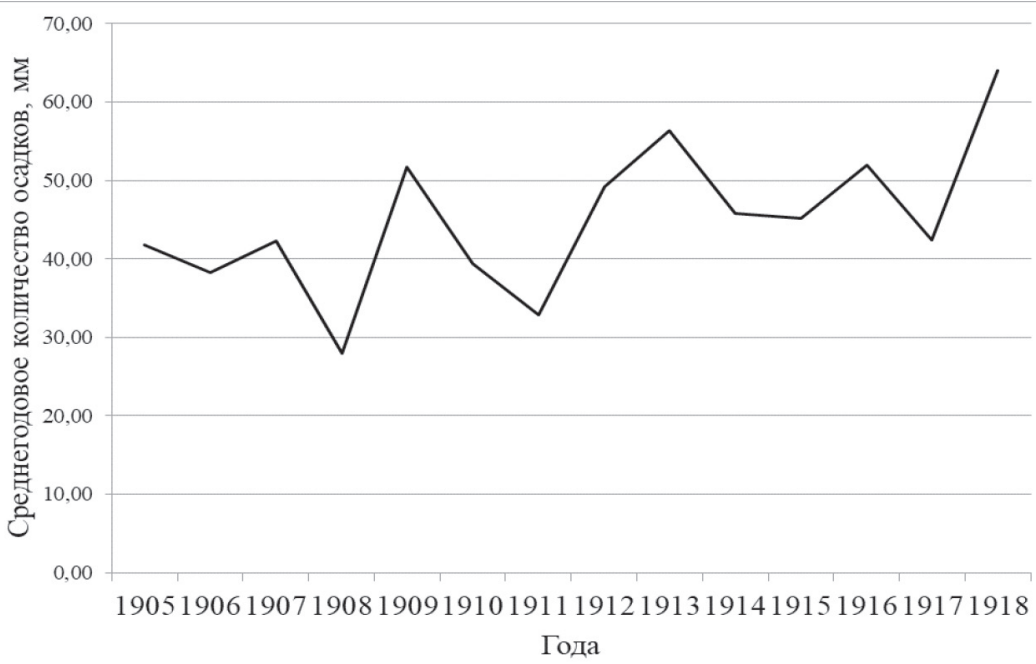

Рис. 2. Динамика среднегодовых осадков с 1905 по 1918 гг. по материалам метеостанции «Боровая ЛОС»

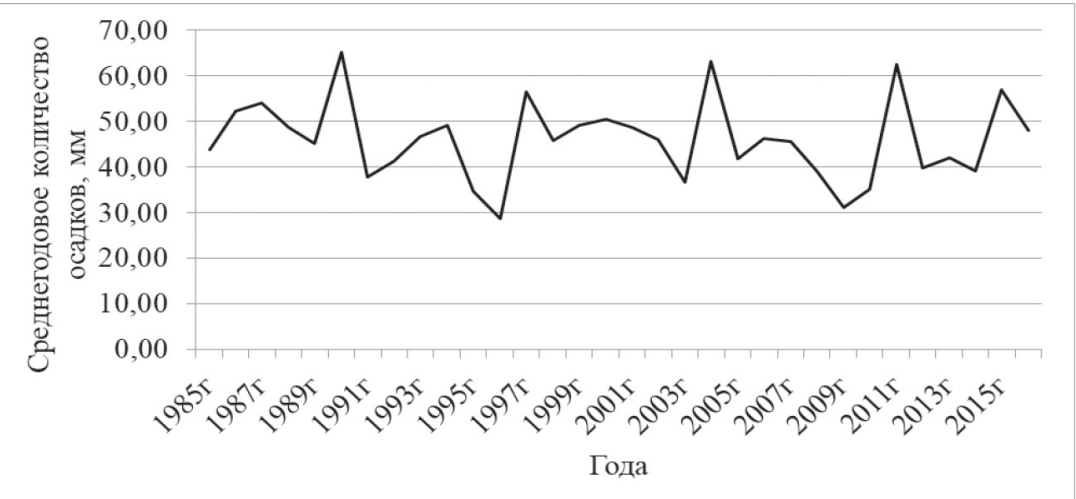

Рис. 3. Динамика среднегодовых осадков с 1985 по 2015 гг. по материалам метеостанции «Боровая ЛОС»

Исследования в других регионах России и Оренбургской области также показывают значительный положительный тренд. На Алтае, например, повышение температуры относительно климатической нормы существует во все сезоны, но наиболее значительны в зимний и весенний период $[5,6]$. 


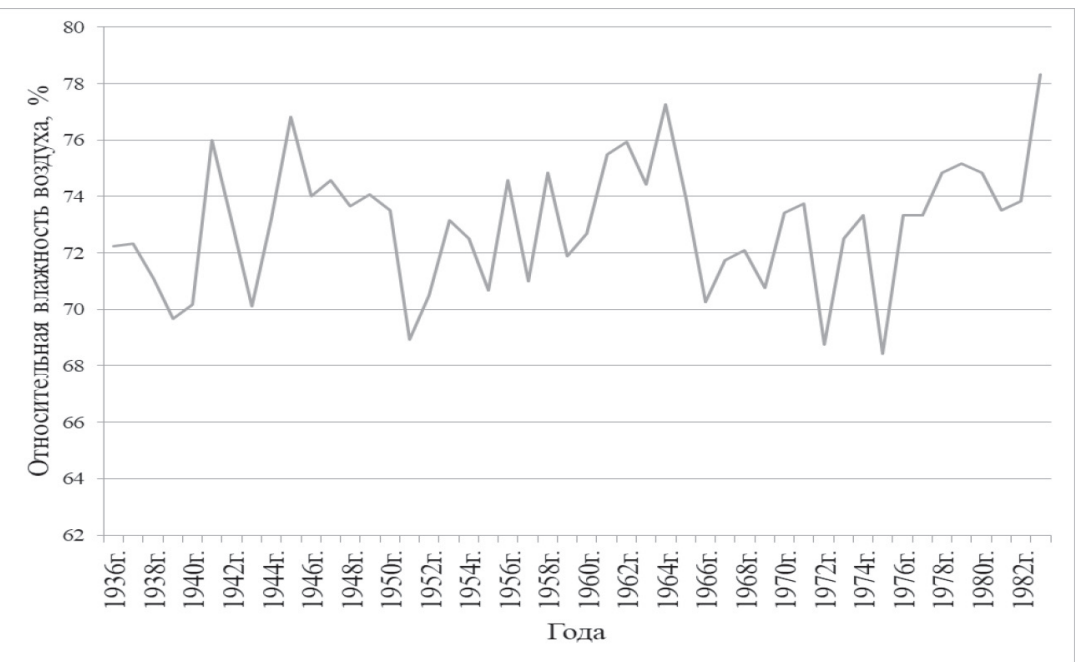

Рис. 4. Динамика среднегодовой относительной влажности воздуха с 1936 по 1983 гг. по материалам метеостанции «Боровая ЛОС»

С 1961 года зафиксирован рост и в соседних государствах. В Астане скорость повышения в среднем составляет $0,3^{\circ} \mathrm{C}$ за каждые 10 лет [7].

В результате проведенной работы был выявлен положительный тренд по среднегодовой температуре, среднегодовому количеству осадков. При этом наблюдаются незначительные колебания относительной влажности воздуха. Повышение температуры может представлять угрозу для устойчивости экосистемы Бузулукского бора, поэтому необходимы дальнейшие исследования (расчет экологических рисков, снижение антропогенной нагрузки) для разработки системы мероприятий, компенсирующих его негативное влияние, мониторинг за распространением болезней и вредителей, которые обуславливаются возрастающим антропогенным влиянием и в частности повышением среднегодовых показателей температуры.

\section{Список литературы}

1. Годнев Е.Д. Бузулукский бор. М.: Гослесбумиздат, 1953. 95 с.

2. Даркшевич Я.Н. Бузулукский бор. Чкалов, 1953. 88 с.

3. Положение о Федеральном государственном учреждении «Национальный парк «Бузулукский бор» / Приказ Министерства Природных Ресурсов Российской Федерации №27 от 04.02.2008. 22 с. 
4. Бузулукский бор: эколого-экономическое обоснование организации национального парка / Под ред. А.А. Чибилева. Екатеринбург: УрО РАН, 2008. $186 \mathrm{c}$.

5. Сухова М.Г. Современные изменения температурного режима воздуха и режима увлажнения на Алтае, как проявление регионального изменения климата / М.Г. Сухова, Т.Д. Модина // Мир науки, культуры, образования. №.2 (5). 2007. С. 14-18.

6. Агафонов Л.И. Изменение климата прошлого столетия и радиальный прирост сосны в степи Южного Урала / Л.И. Агафонова, В.В. Кукарских // Экология. №3. 2008. С. 173-180.

7. Кожахметова Э.П. О климате и его изменении в городе Астане / Э.П. Кожахметова, П.Ж. Кожахметов // Гидрометеорология и экология. №2. 2011. C. $7-14$.

\section{References}

1. Godnev E.D. Buzulukskij bor [Buzuluk forest]. Moscow: Goslesbumizdat, 1953. $95 \mathrm{p}$.

2. Darkshevich Ja.N. Buzulukskij bor [Buzuluksky boron]. Chkalov, 1953.88 p.

3. The Statute on the Federal State Institution "National Park "Buzuluksky Bor" / Order of the Ministry of Natural Resources of the Russian Federation No. 27 dated 04.02.2008. $22 \mathrm{p}$.

4. Buzulukskij bor: jekologo-jekonomicheskoe obosnovanie organizacii nacional'nogo parka [Buzuluksky Bor: an ecological and economic justification for the organization of a national park] / ed. A.A. Chibilev. Ekaterinburg: UrO RAN, 2008. $186 \mathrm{p}$.

5. Suhova M.G., Modina T.D. Sovremennye izmenenija temperaturnogo rezhima vozduha i rezhima uvlazhnenija na Altae, kak projavlenie regional'nogo izmenenija klimata [Current changes in the temperature regime of air and moisture regime in the Altai, as a manifestation of regional climate change]. Mir nauki, kul'tury, obrazovanija [The World of Science, Culture, Education]. № 2 (5). 2007, pp. 14-18.

6. Agafonov L.I., Kukarskih V.V. Izmenenie klimata proshlogo stoletija i radial'nyj prirost sosny v stepi Juzhnogo Urala [Climate change of the last century and radial growth of pine in the steppes of the Southern Urals]. Jekologija [Ecology]. No. 3. 2008, pp. 173-180.

7. Kozhahmetova Je.P., Kozhahmetov P.Zh. O klimate i ego izmenenii v gorode Astane [On the climate and its change in the city of Astana]. Gidrometeorologija i jekologija [Hydrometeorology and Ecology]. №2. 2011, pp. 7-14. 


\section{ДАННЫЕ ОБ АВТОРАХ}

Кожакин Петр Алексеевич, аспирант БашГУ

Бузулукский гуманитарно-технологический институт (филиал) ФГБОУ ВО ОГУ

ул. Комсомольская, 112, г. Бузулук, 461040, Российская Федерация PeterKZ@yandex.ru

Хазиахметов Рашит Мухаметович, доктор биологических наук, профессор ФГБОУ ВО Башкирский государственный университет ул. Заки Валиди, 32, г. Уфа, 450076, Российская Федерация eco3110@rambler.ru

\section{DATA ABOUT THE AUTHORS}

Kozhakin Petr Alekseevich, Postgraduate of Bashkir State University Buzuluk Institute of Humanities and Technology (branch) Orenburg State University

112, Komsomolskaya Str., Buzuluk, 461040, Russian Federation PeterKZ@yandex.ru

Haziahmetov Rashit Muhametovich, Doctor of Biological Sciences, Professor Bashkir State University 32, Zaki Validi Str., Ufa, 450076, Russian Federation eco3110@rambler.ru 